\title{
DE LOS USOS DEL CANON: EL CANON POR VENIR Y EL LAZARILLO DESFIGURADO
}

\author{
Manuel ASENSI PÉREZ \\ Universidad de Valencia \\ manuel.asensi@uv.es
}

\begin{abstract}
Resumen: Este ensayo propone una concepción «plástica» de canon en la que éste adopte la forma de una constante «por venir», un canon abierto por sus bordes en cuya confección participe un conjunto colectivo y democrático de agentes sociales en representación de las diferentes razas, géneros y clases que componen una comunidad determinada. Para ello es necesario ejercer una crítica tanto correctiva como radical. Sin embargo, igual de necesario es usar e interpretar las obras canónicas de acuerdo con los intereses de esas comunidad heterogénea. Ello supone emplear una forma de lectura como sabotaje que ponga de relieve las modelizaciones que lleva a cabo un texto. Con ese fin, este ensayo pone un ejemplo de ese tipo de lectura tomando como hilo conductor el Lazarillo de Tormes. La tesis que se defiende a este respecto es que el Lazarillo aporta un modelo de análisis político que contribuye al debate contemporáneo sobre la subalternidad.
\end{abstract}

Abstract: This essay proposes a «plastic» assumption of the canon in which it adopts the form of a permanet «foth-coming», a canon edge-oponed done 
by a set of collective and democratic social agents representing different races, genres and classes of a community. In order to reach that objective it is necessary to play a corrective and radical criticism. But it is important too to use and interpret the canonical works acording to the interest of that heterogen community. It implies to use a kind of reading as a sabotage that underlines the modelization of the work. This essay illustrates that kind of reading taking as a guiding point the Lazarillo de Tormes. In this respect, it defends that Lazarillo suposes a model of political analysis that contributes to the contemporary debate on subalternity.

Palabras clave: Teoría del canon. Lazarillo de Tormes. Crítica como sabotaje. Subalternidad.

Key words: Theory of the Canon. Lazarillo de Tormes. Criticism as a sabotaje. Subalternity.

\section{I}

No pretendo plantear la cuestión del canon en los términos de una ética de la lectura. Toda la discusión en torno a la complicidad entre el canon y el falogocentrismo, entre el canon y el colonialismo, choca con el hecho contumaz de que toda formación social produce un sistema de valores que selecciona un conjunto de textos y excluye otros. Tal sistema de valores, Nietzsche lo sabía bien, es el resultado de una construcción social que sólo alguien ingenuo o perverso puede tomar por universal y transhistórico. Ahora bien, decir de algo que es una «construcción» no significa que sea liviano o que se pueda sustituir fácilmente por otra construcción sin más ni más. Las nociones heideggerianas y gadamerianas de «prejuicio» y «precomprensión» han curado a muchos y a muchas de la enfermedad consistente en pensar que todo trabajo político consiste en quitar de en medio dichos prejuicios y precomprensiones. No obstante, la actitud contraria, la de limitarse a vivir tranquilamente dentro de los esquemas entregados por la tradición, tal y como ha hecho Harold Bloom, es más perniciosa que la anterior.

Lo que Boltanski y Chiapello reivindicaron como función transformadora de la crítica, se presenta como la única solución posible para una concepción plástica del canon. En efecto, estos autores indican que hay dos maneras de ejercer la crítica: la correctiva y la radical. En el primer caso, se trata de demostrar que en una determinada prueba (elecciones, exámenes, negociacio- 
nes, etc.) se ha transgredido la justicia, hecho que ha favorecido a unos a costa de otros. El objetivo de esta crítica sería «mejorar la justicia de la prueba» (Boltanski y Chiapello, 1999: 78). En el segundo caso, no se pretende corregir las condiciones de la prueba para hacerla más justa sino «suprimirla y, eventualmente, reemplazarla por otra» (Boltanski y Chiapello, 1999, 79). Así, por ejemplo, cuando Lillian S. Robinson (2007) reclamaba una humanización del canon que hiciera sitio a «another literary reality, which joined with the existing canon,» estaba poniendo en práctica un tipo de crítica correctiva. Sin embargo, los ataques de Kate Millet contra el carácter patriarcal de algunos autores canónicos ingleses (como N. Mailer, H. Miller o D. H. Lawrence) puede ser comprendido, sin duda, como un ejemplo de crítica radical.

Si con Walter Mignolo (1991: 251) aceptamos que «la formación del canon en los estudios literarios no es más que un ejemplo de la necesidad de las comunidades humanas de estabilizar su pasado, adaptarse al presente y proyectar su futuro», se comprenderá que el núcleo esencial de este hecho recae en la noción de «comunidad». La bien conocida definición de «nación» dada por Benedict Anderson (1983) como «comunidad política imaginaria», pone sobre la pista de la función cohesiva que el arte ha podido tener a lo largo de la historia ${ }^{1}$. Las sucesivas interpretaciones que desde el siglo XIX se vinieron haciendo a propósito de D. Quijote de la Mancha como expresión de una de las características propias de lo «español»; la labor, por ejemplo, de Unamuno y la generación del 98 en torno al casticismo y el carácter quijotesco de los «españoles», habla sin demasiados tapujos de la función performativo-cohesiva de la imaginación literaria. La profundidad y el calado del llamado quijotismo en la comunidad española es un síntoma inequívoco de lo que estoy argumentando. Ello revela hasta qué punto lo referido al canon es de orden político, y también la necesidad de que en toda reflexión sobre él entren necesariamente en juego tales factores.

El problema, naturalmente, es que toda reflexión sobre el canon debería tener en cuenta la determinación geopolítica del sujeto, así como el carácter plural de éste. La crítica que Spivak (1988) lanzó contra Foucault-Deleuze iba precisamente en esa dirección: si se hace la crítica de la tendencia homogeneizadora de las ideologías reaccionarias, no se puede a renglón seguido presuponer un sujeto revolucionario colectivo y unificado. Es por ello que no se puede obliterar el hecho de que ni todos los grupos ni sujetos

\footnotetext{
1 Véase al respecto el ya clásico libro de A. Ahmad (1992).
} 
que forman una comunidad, ni todas las comunidades, pueden estabilizar su pasado, adaptarse al presente y proyectar su futuro a partir de la misma lista de textos literarios, ni siquiera a partir de la misma manera de interpretarlos.

La fuerte heterogeneidad de género, raza y clase en el seno de una comunidad lleva aparejado el que no todos sus componentes puedan sentirse apelados por parte de un mismo conjunto de textos. Si se argumenta que un texto canónico se define por su permanencia e indestructibilidad, por el hecho de que continúa hablando a nuestro horizonte de expectativas más allá de una determinación temporal (Gadamer, 1960: 244), se incurre en el error de presuponer que ese «nuestro» representa un sujeto compacto y unitario. Es cierto que en la medida en que se acude a la comunidad para definir y explicar el canon, resulta fácil comprender igualmente que no se puede ir en contra de ella sin socavar de alguna manera su propia identidad. De ahí que la crítica más efectiva de un canon determinado sea del tipo correctivo en aquellas comunidades que ya tienen tras de sí una larga tradición, y que la crítica radical funcione más adecuadamente en el caso de las literaturas emergentes ${ }^{2}$.

Tanto en un caso como en otro sería interesante, y aquí se encuentra el núcleo de lo que argumento en este terreno, que habláramos de un «canon por venir», un canon abierto por sus bordes, un canon plástico, en cuya revisión, confección y mantenimiento participara un conjunto colectivo y democrático de agentes y actores sociales en representación de las diferentes instituciones y grupos que constituyen una comunidad determinada.

Sin embargo, en este ensayo no pretendo tratar, más allá de lo comentado en estos párrafos iniciales, ese problema arduo tan zarandeado. En realidad, quisiera introducir mediante un ejemplo una discusión en torno a los usos del canon. Entiendo por «uso del canon» la manera en que usamos e interpretamos los textos canónicos de una determinada tradición literaria. Desde una posición radical, un canon determinado sólo puede ser saboteado de dos maneras: o bien mediante uno de los dos ejercicios críticos que acabo de mencionar (sustitución parcial o total de las obras que componen un canon), o bien haciendo lecturas desacralizadoras de las obras consideradas como canónicas. Un ejemplo bien conocido de lectura desacralizadora fue la que llevó a cabo en 1963 Roland Barthes con la publicación de su obra Sur Racine (1963). La lectura psicoanalítica de Fedra en los términos de la prohibición del incesto, el empleo de los presupuestos de la antropología es-

\footnotetext{
2 Véase a este respecto el texto de Wlad Godzich (1977).
} 
tructural puesta en circulación años antes por Lévi-Strauss, fueron considerados por la crítica tradicional, y por su representante Raymond Picard (1965), como escandalosos. ¿Por qué? Porque desfiguraba la obra emborronando las pistas de época, porque había hecho desaparecer la obra literaria y porque había puesto en evidencia los peores defectos del espíritu.

La reacción de la crítica ante la lectura de Roland Barthes constituye el síntoma de una movilización y desplazamiento de una obra considerada en Francia como canónica. No se equivocaba Robert Louis Junod cuando desde las páginas de La tribune de Genève (1963) se refería a la nueva luz que Barthes había proyectado sobre el universo raciniano. Esa nueva luz desestabilizaba a Racine y el canon que él representaba poniéndolo en diálogo con un discurso que a los ojos de muchos críticos le resultaba antitético, el psicoanálisis.

Muchos especialistas se han preguntado por qué Derrida sólo tomaba como objeto o sujeto de la deconstrucción a figuras canónicas de la filosofía y la literatura como Platón, Aristóteles, Husserl, Heidegger, Mallarmé, Joyce, Celan o Poe, entre otros muchos. La respuesta a esta pregunta no puede ser simple ni sencilla, pero hay un aspecto de ella que sí me atrevo a enunciar. El hecho de que Derrida (1968) hallara en Platón contradicciones, términos con un haz semántico antitético (como el pharmakon) ${ }^{3}$, diseminaciones, líneas argumentales que subvertían el argumento central, venía a desacralizar esos autores canónicos o demostraba que ellos mismos, como era el caso de Mallarmé, eran auténticas máquinas de guerra en contra del pensamiento metafísico. Quiero decir que al hacer ese tipo de lecturas, Derrida estaba atacando la dimensión institucional y esterilizante del canon filosófico y literario. Las diferentes e incesantes aproximaciones de Ph. Sollers (1968 y 2000) a Dante iban en una dirección muy semejante. En todos esos casos, el resultado fue corrosivo.

En las páginas que siguen trato de afrontar esa cuestión de la lectura desacralizadora de las obras del canon tomando como guía una de las obras que forman parte del canon de la literatura española del siglo XVI, el Lazarillo de Tormes. En el curso de mi ejercicio crítico parto del supuesto de que una lectura que sabotee dicha obra en nuestro contexto no puede ser sino política, tratando de buscar lo que esa obra puede aportar al horizonte que nos envuelve en los inicios del siglo XXI. Con ese fin, vale la pena declarar ya desde ahora que el Lazarillo de Tormes es una obra trágica (por muchos recursos

3 Véase «La pharmacie de Platon», en Derrida (1972: 67-197). Originalmente publicado en la revista Tel Quel (1968). 
humorísticos que emplee) cuyo silogismo plantea de una manera muy clara lo que sucede con el subalterno cuando tiene hambre. En la ingente bibliografía sobre esa pequeña obra magistral se olvida muchas veces que la realidad contundente y sin paliativos del Lazarillo es que pasa hambre y que, a causa de ello, muchas veces está a punto de morir. La frase «Finalmente, yo me finaba de hambre» (LT, 49) ${ }^{4}$ se repite con múltiples variantes a lo largo de la obra. Es por ello que en estas páginas argumento que el Lazarillo de Tormes es un documento esencial en el debate sobre la subalternidad tal y como se ha venido desarrollando desde mediados de los años ochenta.

\section{II}

De hecho, el objeto de este ensayo no anda lejos de las preocupaciones que, iniciadas por el Grupo de Estudios Subalternos (formado por intelectuales indios como Ranajit Guha, Dipesh Chakravarty, Partha Chatterjee o Gautam Barda de Guja), ha llegado hasta nosotros de la mano de Gayatri Chakravorty Spivak, Benita Parry, Homi Bhabha, Aijaz Ahmad, Walter Mignolo o John Beverly, entre otros. Sin embargo, la manera de proceder aquí guarda una especificidad propia, en la medida en que trata de analizar, con un criterio más o menos extraído de la narratología y del análisis lingüístico, la potencia política de un texto «literario», o por ser más exactos: de un texto que hoy en día forma parte del canon de la literatura clásica española, si bien a mediados del siglo XVI no cabía dentro de los géneros poéticos. No se trata de averiguar la productividad del análisis ideológico cuando las herramientas de los estudios literarios se emplean para analizar la historiografía, la filosofía o la ética, sino de poner encima de la mesa lo que en otro lugar he denominado el «poder de la literatura $»^{5}$.

El texto «literario» al que me refiero es, como se ha dicho anteriormente, el Lazarillo de Tormes, el cual, como plantearé a continuación, proporciona todo un modelo de análisis político. Gracias a este modelo, los problemas derivados de las aproximaciones históricas a la subalternidad adquieren una luz particular ${ }^{6}$.

${ }^{4}$ Las citas de El Lazarillo de Tormes se hacen a través de la 10. ${ }^{a}$ edición de Francisco Rico (1995). El número de página aparece tras la cita entre paréntesis.

${ }^{5}$ Me permito remitir al lector a mi libro Philippe Sollers, Tel Quel y la génesis del postestructuralismo francés (2006).

6 Aunque los estudios subalternos se pusieran de moda, en efecto, a raíz de la aparición del mencionado Grupo de Estudios Subalternos en la India, vale la pena hacer notar que el uso del término «subalterno» era frecuente en la historiografía española de inspiración marxista entre mediados de los sesenta y los años setenta. Véase, por ejemplo, el uso que del término hace José Antonio Maravall (1973³). 
La interpretación «esteticista» del Lazarillo de Tormes, tal y como fue defendida por Marcel Bataillon (1958: 13) y Lázaro Carreter, que sólo ve en él «un tour de force artistique» y una combinación o centón de historietas folklóricas (Bataillon, 1958: 45), adolece de dos serios problemas:

- En primer lugar, ignora que prácticamente hasta el siglo XVIII, todo juicio estético es, a la vez, un juicio ético-político y metafísico. Quiere decirse que todo juicio en torno al valor de belleza de una obra de arte va acompañado necesariamente por un juicio sobre su bondad o maldad (dimensión ético-política) y sobre su verdad o falsedad (o metafísica).

Una ojeada a los debates teórico-literarios del Renacimiento revela la justeza de lo que estoy diciendo. La ascendencia platónica y horaciana del juicio crítico tal y como provenía de la Edad Media obligó a los escritores y críticos a establecer una defensa de la poesía en la que ésta era integrada muchas veces dentro de la filosofía moral. Es más, tal y como puso de relieve Weinberg en su libro sobre la crítica literaria en el Renacimiento, «Objectors and defenders alike operated in the Platonic mode insofar as they subordinate the ends of poetry to the ends of the state [...] The question was one of utility and of instruction: could poetry, by making men morally better, contribuye to their moral instruction and hence, indirectly, to the common weal?» (Weinberg, 1961: II, 798-799) ${ }^{7}$. Así, el marco del debate renacentista en torno a la Divina Commedia de Dante, Canace e Macareo de Sperone Speroni, Orlando Furioso de Ariosto, Gerusalemme Liberata de Tasso y el Pastor Fido de Guarini, debate que está teniendo lugar en el mismo momento histórico en que se publica el Lazarillo de Tormes, posee un fondo sin duda ético-metafísico.

Por ejemplo, cuando Sassetti defiende la Divina Commedia de las acusaciones de inverosimilitud (que constituía uno de los núcleos de la polémica), aduce dos argumentos: que la verosimilitud depende de la asunción de la gracia divina, y que personajes como los pecadores en el canto del Inferno aparecen con un fin claramente moral: deben ser castigados, al igual que todo comportamiento pecaminoso. La conocida frase de Petrarca «veritatem rerum pulchris velaminibus adornare», dicha a propósito del mecanismo alegórico que consiste en oscurecer la verdad tras el velo de una ficción bella, fue continuada y desarrollada a lo largo del Renacimiento. Y así un largo et-

7 «Tanto los objetores como los defensores se comportaban de un modo platónico en la medida en que subordinaban el fin de la poesía al fin del estado [...] La cuestión se refería a la utilidad e instrucción: ¿puede la poesía, haciendo a los hombres moralmente mejores, contribuir a su instrucción moral y, por ello, al bien común?». 
cétera que el lector puede encontrar bien documentado en los trabajos de Spingarn (1963), Weinberg (1961) y García Berrio $(1977,1980)$, entre otros.

- En segundo lugar, es una interpretación que no asume la posibilidad de que la mención de un texto, pongamos por caso, puede ir de la mano de su uso. Aunque sea necesario distinguir cuándo una expresión es empleada, y cuándo es citada, es claro que todo uso viene posibilitado por la repeticiónmención de una determinada secuencia. Tal y como puso de relieve Derrida (1967: 99) «cuando me sirvo [...] de palabras, lo haga o no con fines comunicativos [...] debo, desde el comienzo, operar (en) una estructura de repetición». Eso significa que por mucho que el Lazarillo de Tormes suponga la reiteración de historias folklóricas o de otro tipo de fuentes literarias y no literarias (Apuleyo, Luciano, el Baldo, El Crotalón, las carte messaggiere, etc.) (Rico, 1995: 13-139), su performatividad, sus efectos y sus diferentes usos están fuera de toda duda. De otro modo, resultaría muy difícil explicar, entre otros muchos acontecimientos, la aparición en 1573 de un Lazarillo castigado (2000) debido a la censura del celo inquisitorial. Fernando de Valdés, a la sazón inquisidor general, no debió tener la impresión de que el Lazarillo de Tormes era ni un juego estético, ni tampoco un motivo para la risa.

Y de eso se trata precisamente: de analizar la posición de esta obra en el conjunto del polisistema de mediados del siglo $\mathrm{XVI}^{8}$, su incidencia política y performativa.

\section{III}

Entre las diferentes definiciones del/a subalterno/a dadas por Gayatri Chakravorty Spivak, hay una que nos ayudará a comprender de manera más precisa la figura del Lazarillo. En ella se afirma que el/a subalterno/a es aquel o aquella que más que actuar, sufre las acciones de otros ${ }^{9}$. Si fijamos la atención en el Lazarillo veremos que ello es rigurosamente cierto, y no tanto porque él no lleve en muchos momentos la iniciativa, sino porque incluso cuando lleva a cabo sus «picarescas» son re-acciones más que acciones. Se

${ }^{8}$ Para la teoría de los polisistemas véase naturalmente la obra de Itamar Even-Zohar (1990), por ejemplo el volumen monográfico de la revista Poetics Today (1990), número titulado precisamente «Polysystem Studies». Una exposición clara de dicha teoría se encuentra en Montserrat Iglesias Santos (1994).

9 Esta definición se encuentra en el texto «The New Subaltern: A Silent Interview», Vinayak Chaturvedi (ed.) (2000: 326). 
puede decir que tanto Lázaro como el Lazarillo sufren una serie de acciones de aquellos que están por encima de él y que, a causa de ello, se ve en la necesidad de actuar con el fin de poder sobrevivir. Lázaro y Lazarillo son sujetos pasivos y reactivos.

No es porque sí que las interpretaciones psicoanalíticas y escatológicas del Lazarillo hayan enfatizado el papel «pasivo» del personaje. Así, por ejemplo, Ferrer-Chivite (1983) afirmó que la figura del arcipreste «además de ponerle los cuernos a Lázaro, lo sodomiza». En su opinión, el fragmento «tengo en mi señor arcipreste todo favor y ayuda. Y siempre en el año le da, en veces, al pie de una carga de trigo, por las Pascuas, su carne; y cuando el par de los bodigos, las calzas viejas que deja» (LT, 131) ha de interpretarse identificando las «calzas» con el órgano sexual masculino, los «bodigos» como los testículos y el «trigo» como el semen. Y como quiera que quien «da» es el arcipreste, quien recibe es Lázaro y su mujer.

En conclusión, Lazarillo se define como personaje más por sufrir las acciones de los demás que por realizar él mismo acciones. Todo comienza por la enunciación misma. Si comprendemos esta como «la instancia de mediación que asegura la aparición de un enunciado-discurso», o como «la estructura no lingüística (referencial) subtendida por la comunicación lingüística $\gg^{10}$, entonces resulta claro que la iniciativa del acto de enunciación en virtud del que Lázaro se dirige a «Vuestra Merced» no ha dependido de él. Desde el momento en que en el «Prólogo» afirma «Y pues Vuestra Merced escribe se le escriba» (LT, 10), y más allá de la estructura retórica a la que tal frase remite, es patente que Lázaro es un sujeto demandado. Un sujeto que escribe porque le piden que lo haga. Quién sea ese personaje que se esconde tras la fórmula de cortesía «Vuestra Merced», se trate de un hombre o de una mujer ${ }^{11}$, ocupe una posición más o menos elevada, no cambia el hecho de que Lázaro responda en tanto en cuanto se siente apelado.

Esto quiere decir, sea como fuere, que Lázaro no puede tomar la palabra por sí mismo cuando quiera y como quiera, sino sólo en el caso de que una instancia se lo requiera. El poderoso se define por poder tomar la palabra en

10 Según la definición de «enunciación» que dan Greimas y Courtés (1979: 144).

${ }^{11}$ La frase del tratado VII, «hablando con reverencia de Vuestra Merced, porque está ella delante» (LT 33), y más en concreto el pronombre «ella», ha sido interpretado por Rosa Navarro Durán (2003: 18) como referido a una mujer: «ese "Vuestra Merced" es una mujer, por eso dice "ella". Todo cobra sentido entonces». No son pocas las consecuencias que se desprenden de esa interpretación bien justificada, y no sólo en lo que se refiere al carácter converso del autor, Alfonso de Valdés, y a su ascendencia erasmista, sino también en cuanto al tipo de relaciones surgidas cuando quien interroga es un sujeto marginado considerado como un eterno menor de edad. 
contextos muy amplios, mientras que el subalterno se define por no poder tomar la palabra bajo su propia iniciativa. Esta manera de definir la subalternidad no coincide con la tesis de Spivak (1988: 271) según la que el subalterno no puede hablar, sino que subraya el hecho de que no puede hablar cuando quiere. Un acto de habla necesitado de una sanción institucional sólo puede ser realizado por el/a subalterno/a en el caso de ser requerido para ello. Es precisamente lo que sucede con Lázaro. El problema radica precisamente en las consecuencias que ese acto de habla forzado por el Otro puede acarrear.

Porque en el caso de hablar a instancias del Otro ¿quién está hablando en realidad? Como mínimo debe reconocerse que nos encontramos ante un conjunto de signos multiacentuados, en el sentido en el que Voloshinov (1929) habló de la multiacentuación, dialogismo y alteridad en el lenguaje. ${ }^{12}$ No es extraño que la crítica haya ido señalando desde temprano que una de las principales características del lenguaje del Lazarillo es la ironía. Al iniciar el prólogo con la alusión a las «cosas tan señaladas, y por ventura nunca oídas ni vistas» (LT, 3), quien así escribe hace dos acciones a la vez: 1) reproducir una fórmula de captatio benevolontiae que se remonta como mínimo a Horacio; 2) boicotear esa fórmula por cuanto las «cosas» a las que se refiere no sólo son conocidas por el entorno del protagonista, sino que también pertenecen a un orden miserable. La relación entre (1) y (2) es de ironía, en la medida en que un sentido provoca la deconstrucción y desautorización del otro. La mención del «grosero estilo» (LT, 9) en que escribe pone de relieve que las significaciones enfrentadas propias de la ironía se corresponden a una posición desigual de los sujetos que acentúan ese discurso. Si el o la «Vuestra Merced» a la que se dirige no se encuentra por encima de Lázaro, ${ }^{13}$ mal se explica que éste responda de una situación que, en realidad, supone un deshonor y una vergüenza para su persona.

En su «respuesta» Lázaro guarda el mismo equilibrio que la figura de la Templanza en el Tarot de Marsella debe guardar cuando transfiere el líquido de una copa a otra, y toda la creatividad lingüística responde al esfuerzo de explicar lo que posiblemente es inexplicable. Es por ello por lo que me pa-

12 En efecto, en este libro aclara que la expresión «signo multiacentuado» quiere decir que la palabra es el producto de un acto bilateral, que está determinada «en la misma medida por aquel a quien pertenece y por aquel a quien está destinada» (Voloshinov, 1929: 121).

13 Me refiero, claro está, a aquellas interpretaciones de acuerdo con las que el tratamiento de «Vuestra Merced» no supone que el destinatario al que se dirigen se un superior. Véase A. Labertit (1972) y Víctor García de la Concha (1981). De hecho, hay documentados usos en el español de la época en los que el tratamiento a través de «Vuestra Merced» se refiere a un personaje que ocupa una posición superior a la del destinador. Por ejemplo, en las epístolas de Antonio de Guevara (2004: 287). 
rece del todo evidente que quien reclama de Lázaro una respuesta y le da la palabra tiene que ser alguien que se encuentra en disposición de exigir esa acción. De hecho, y por paradójico que pueda parecer, Lázaro se encuentra lo suficientemente cómodo (entiéndase esto como una alusión al comer y al vestir), como para, tras las experiencias de subalterno profundo por las que ha atravesado, quedarse callado como camaleón. Si toma la palabra es porque se ve en la obligación de hacerlo.

Así, pues, el discurso de Lázaro está multiacentuado y en él se halla la presencia del Otro. Sin embargo, tal multiacentuación no refleja un diálogo de tú a tú, sino una pelea entre desiguales, entre quien ocupa una posición de subalterno y quien se encuentra en una posición de dominio, tanta al menos como para exigir una respuesta. Es a este hecho al que me refería cuando hablaba de que Lazarillo es un subalterno caracterizado por su pasividad y reactividad.

La enunciación de su respuesta permite precisamente que se descubra como figura subalterna. Si Heidegger (1927: 325) afirmaba que «Der Ruf weist das Dasein vor auf sein Seinkönen und das als Ruf aus der Unheimlichkeit» ${ }^{14}$, podemos invertir esta fórmula a la hora de aplicarla al Lazarillo: la llamada sitúa al Dasein ante su «impotencia-para-ser», y lo hace, eso sí, como llamada que viene de un lugar inhóspito (el misterioso «Vuestra Merced»). Es la razón de la indeterminación del o de la «Vuestra Merced». Que esta figura permanezca desconocida es la condición para que se presente como llamada que reclama el «veni foras» a Lázaro. Es precisamente esta llamada la que saca a Lázaro del mundo de los muertos en vida, del subalterno cuya única salida es el puro nihilismo del cinismo y el desencanto. Al llamarle le obliga a un acto de reflexividad a partir del que presenta su condición y le salva del silencio y del olvido. Función paradójica, por tanto, la de esa llamada, pues determina la posición subalterna de Lázaro y, a la vez, le saca, si quiera vergonzosamente, de su anonimato.

\section{IV}

Pero el análisis de la tropología del Lazarillo nos lleva un poco más lejos. Tal y como acabamos de ver, la respuesta al Otro supone el empleo dividido del lenguaje, y en una gran cantidad de casos esa división se manifiesta

14 «La llamada sitúa al Dasein ante su «potencialidad-de-ser», y lo hace como llamada que proviene de lo inhóspito [siniestro].» 
bajo la forma de una deconstrucción de las ideas recibidas, más en concreto, de las unidades fraseológicas. Cuando éstas se presentan bajo la forma de una paremia arrastran con ellas un determinado modelo de mundo. Quiere decirse que manifiestan un juicio moral, o establecen una ley o señalan un acontecimiento futuro.

Así sucede, por ejemplo, con el refrán «Donde una puerta se cierra, otra se abre», el cual es empleado por Lázaro en mitad del relato de su estancia al servicio del clérigo de Maqueda. Cobarruvias (1977: 886) señala que «abrir puerta, es dar ocasión», dando a entender que aunque se pierda en algún momento una oportunidad, siempre habrá otra. El carácter idiomático del refrán en cuestión se observa en su componente alegórico donde el plano literal del término «puerta» sirve para aludir figuradamente, por analogía, a diferentes situaciones vitales. En este caso, Lázaro está narrando cómo el hambre le avivó el ingenio: con un cuchillo viejo practicaba agujeros en el arca donde el clérigo guardaba el pan con el fin de hacerle creer que los responsables del hurto eran unos ratones. Mediante un empleo maestro de los tiempos verbales pasado y presente, el narrador refiere el trajín de su amo tapando con tablas los agujeros y él con el cuchillo haciéndolos:

Torna a buscar clavos por la casa y por las paredes, y tablillas a atapárselos. Venida la noche y su reposo, luego era yo puesto en pie con mi aparejo, y cuanto él tapaba de día destapaba yo de noche (LT, 64).

Es el complejo psicológico de la intencionalidad significativa el que engloba el uso del refrán mencionado: «En tal manera fue y tal priesa nos dimos, que sin dubda por esto se debió decir: "Donde una puerta se cierra, otra se abre"». El humor negro de este discurso, si algo puede haber de humor en el padecimiento de hambre, radica en que el narrador es consciente de que esos hechos no pueden estar en el origen de tal expresión que él ha recibido de la tradición lingüístico-expresiva de su comunidad. También es consciente de que ese refrán no designa tanto una realidad material cuanto una determinada situación de la vida.

Sin embargo, Lázaro rompe el refrán al hacer que su referencia se ajuste al hecho material de que mientras el clérigo cerraba el agujero, él lo abría. Es más: su sabotaje se basa en que mientras el refrán alude a oportunidades que tienen su causa más allá de la voluntad de un sujeto, en un plano de inmanencia, el uso que de él hace Lázaro implica un acción voluntaria del propio personaje. Si se abre otra puerta-agujero en el «arcaz» no es por alguna clase de provisión divina, sino por las insistentes acciones de Lazarillo en busca de su pan. 
Algo semejante ocurre con la variante del refrán «allégate a los buenos y serás uno de ellos» empleada por Lázaro para describir lo que hizo su madre una vez enviudada: «Mi viuda madre, como sin marido y sin abrigo se viese, determinó arrimarse a los buenos, por ser uno dellos.» (LT 15) La idea de Bajtín-Voloshinov (1929: 49) según la que las luchas de clase dejan su huella en los signos se puede apreciar en todo su esplendor aquí. Mientras los grupos sociales que debido a su situación económica pueden sostener una posición y una enunciación ética que distingue los que son moralmente buenos de los que son malos, las subalternas, como es el caso de la madre de Lazarillo, no pueden sino concebir lo bueno en términos estrictamente materiales. Buenos son aquellos que comen y dan de comer. Por eso el signo «buenos» se divide en significaciones contrarias y mutuamente excluyentes aludiendo por una parte a la bondad moral y, por otra, a la bondad material. Además, la fractura del signo lingüístico «buenos» arrastra consigo el verbo «arrimarse», el cual queda asimismo dislocado entre una significación moral consistente en frecuentar a los que son moralmente buenos, y una significación material que se concreta en el arrimarse físico de la prostitución. Ella se arrimaba a «ciertos estudiantes» y a «ciertos mozos de caballos del Comendador de la Magdalena, [precisamente la Magdalena] de manera que fue frecuentando las caballerizas» (LT 15).

No hace falta defender con mucho ahínco que el mismo análisis puede aplicarse a ese momento del final de la narración cuando Lázaro le dice al Arcipreste de Sant Salvador «Señor [...] yo determiné de arrimarme a los buenos» (LT 133) ${ }^{15}$. De nuevo los términos «buenos» $\mathrm{y}$ «arrimarme» sufren en este caso una dislocación de sus significados.

No otra cosa cabe decir del empleo saboteador de aquellas expresiones provenientes de la Biblia. Cuando Lázaro cuenta que su padre, a causa de unos robos en los costales, «padesció persecución por justicia» y dice a continuación «Espero en Dios que está en la gloria, pues el Evangelio los llama bienaventurados» está creando un complejo significativo muy ácido. Si el Evangelio, en efecto, llama bienaventurados a los que sufren persecución por la justicia es debido a que los cristianos son poseedores una verdad profunda más justa que la de la justicia en el poder.

En un primer nivel, el sabotaje de la frase evangélica se origina en que su padre no sufrió persecución por llevar con él una verdad profunda en contra

15 Dislocación que llevó a algunos autores a interpretar la figura del Lazarillo como sujeto diabólico. Así, por ejemplo, Edmond Cros (1976-1977) habló de «la naturaleza satánica del mozo de ciego». 
de la justicia, sino por transgredir una ley humana y divina que dice «no robarás». Los cristianos, dice Jesucristo, serán por su causa arrastrados ante las autoridades y azotados en las sinagogas (Mateo 17), y en eso serán bienaventurados y entrarán en el reino de los cielos. El padrastro de Lazarillo es también arrastrado ante las autoridades y azotado, pero no por la causa cristiana, sino por el hambre extrema en que vive.

Ahora bien, en un segundo nivel de sabotaje la frase irónica no se burla del padrastro del Lazarillo sino de la frase misma dado que en un sentido pleno justifica los robos de su padre. A fin de cuentas su padre no hace sino lo que en el futuro hará Lazarillo y todos aquellos que a lo largo de la historia han padecido por hambre: robar. ¿O es que ahora va a resultar que es moral permitir que la gente muera o padezca por hambre? El hambre es el significado trascendental corrosivo que guía la escritura irónica del Lazarillo. Es el propio narrador quien nos confiesa este segundo sabotaje cuando establece la siguiente declaración moral:

No nos maravillemos de un ciego ni fraile porque el uno hurta de los pobres y el otro de casa para sus devotas y para ayuda de otro tanto cuando a un pobre esclavo el amor le animaba a esto (LT, 19).

El análisis podría proseguir en esta dirección largo y tendido, pero me interesa más en este momento poner de relieve que esas operaciones lingüísticas saboteadoras del Lázaro narrador son posibles en virtud del punto de vista que adopta dicho narrador ${ }^{16}$. De acuerdo con las investigaciones que G. Genette desarrolló en Figures III y con los estudios narratológicos en general, el estatuto del narrador del Lazarillo de Tormes se corresponde con la focalización interna propia de la autobiografía (Genette, 1972: 305-306) ${ }^{17}$, y con un relato autodiegético que da lugar a lo que Pouillon denomina «visión con». Sin embargo, el distanciamiento del Lázaro narrador respecto al sujeto del enunciado, Lazarillo, hace que la visión oscile, en realidad, entre la visión desde dentro y la visión desde fuera, y vuelve problemático el carácter

${ }^{16}$ La importancia de la perspectiva en el Lazarillo de Tormes fue contundentemente establecida por Francisco Rico (1970) en su ya clásico estudio La novela picaresca y el punto de vista. Puede verse también el trabajo de Víctor García de la Concha (1981). No obstante, la manera de interpretar la «perspectiva» en el Lazarillo que ofrezco aquí va más allá de la de estos dos trabajos.

17 Véase también, entre otros, J. Pouillon (1970: 58-72); y Antonio Garrido Domínguez (1996: 147$150)$. 
puro de todo relato autobiográfico o pseudoautobiográfico en cuanto a la perspectiva. A diferencia de lo que ocurre en el llamado «monólogo interior», en el que la coincidencia entre el narrador y lo narrado es técnicamente (no filosóficamente) exacta, en la autobiografía la distancia entre el momento de la enunciación, siempre presente, y los hechos narrados, en pasado, arroja dudas acerca de la posición del narrador. De hecho, por mucho que en una autobiografía los acontecimientos se relaten tal y como los vivió el narrador, nadie puede asegurar que éste no los cuente tal y como ahora en el presente los recuerda o no los está manipulando.

En esto el Lazarillo de Tormes plantea una incógnita formidable. Si su carta se origina en respuesta a una demanda del o de la «Vuestra Merced», ¿cómo estar seguros de que no está mintiendo, de que está manipulando los hechos sucedidos según su conveniencia? ¿Cuántos críticos consideran que la defensa que Lázaro hace de su mujer es, en realidad, una falsedad para encubrir el menage à trois por él consentido? Y si arrojamos una sombra de sospecha sobre ese paso final del informe de Lázaro ¿por qué debemos creernos el resto del relato? Tal sospecha nos lleva a la conclusión de que cabe la posibilidad de que la visión de Lázaro sea más bien «desde fuera» y que su «autodiégesis» sea, en realidad, una «heterodiégesis». He aquí un buen ejemplo de lo que Paul de Man denominaba «indecidibilidad»: el relato no proporciona una base segura para que podamos tomar una decisión y ello vuelve impracticable todo ejercicio crítico que pretenda dominar la escena de este texto «literario» ${ }^{18}$.

Sin embargo, ello no impide que podamos asegurar que nos encontramos ante el relato de un subalterno. Lo que el carácter técnico y taxonómico de la narratología impide ver es que la posición del narrador y de los personajes está íntimamente relacionada con el punto de vista del estamento social desde el que se contemplan los acontecimientos históricos. Y es sólo cuando se atiende a esta relación cuando, por ejemplo, se puede apreciar el carácter revolucionario de un texto como el Lazarillo de Tormes.

Para darse cuenta de esto que acabo de decir, vale la pena tener en cuenta la afirmación de Lenin-Althusser según la que lo verdaderamente revolucionario de la filosofía marxista no es la idea de la lucha de clases, ni la del materialismo dialéctico, ni la distinción entre valor de uso y valor de cambio, etc., sino el hecho de que adopta un punto de vista de clase ${ }^{19}$. Lo que se quie-

18 Sobre la «indecibilidad» en los textos literarios la mejor referencia siguen siendo Paul de Man (1979) y J. Hillis Miller (1985).

19 Véase Louis Althusser (1969). 
re decir con ello es que sólo puede haber conocimiento científico de la realidad cuando la historia, los acontecimientos y las situaciones son contemplados desde abajo. Y no cabe duda de que a este respecto el Lazarillo proporciona la pauta acerca de cómo adoptar un punto de vista de clase, no el del proletariado o el de la burguesía (de más está decirlo, clase revolucionaria en el Renacimiento), sino el del subalterno.

Una sencilla observación demostrará lo que acabo de decir: la verdad del Escudero, la del Buldero o la del Cura de Maqueda, ¿cómo habría sido posible descubrirla si no hubiera sido narrada por alguien que se encuentra en la posición más baja de subalterno? ¿Quién podía darse cuenta de los «mañosos artificios» del Buldero? ¿Quién estaba en disposición de saber qué había detrás del espectáculo que montan el buldero y el alguacil? Sin duda Lazarillo, y no porque fuera especialmente inteligente o porque tuviera mucha vista, sino por el lugar subalterno que ocupa. La descripción no puede ser más elocuente:

Cuando él hizo el ensayo, confieso mi pecado, que también fui dello espantado y creí que ansí era, como otros muchos; mas con ver después la risa y la burla que mi amo y el alguacil llevaban y hacían del negocio, conocí cómo había sido industriado por el industrioso e inventivo de mi amo (LT, 123).

Las palabras empleadas dejan pocas dudas: «ensayo», «industriado», «industrioso», «inventivo», remiten a algo que Guy Debord (1968) calificó de «sociedad del espectáculo». Y es que, en efecto, no hay ningún amo de Lazarillo que no actúe en un espectáculo destinado a convertirse en mercancía. Del ciego afirma que «andábase todo el mundo tras él, especialmente mujeres, que cuanto les decía creían. Déstas sacaba él grandes provechos con las artes que digo, y ganaba más en un mes que cien ciegos en un año» (LT, 27). Si el buldero «ensayaba», el ciego practicaba «artes», todo con el fin de engañar a la gente. ¿Y qué hacía el clérigo de Maqueda sino actuar en aquellas ocasiones en las que «mentía falsamente, porque en cofradías y mortuorios que rezamos, a costa ajena comía como lobo y bebía más que un saludador» (LT, 52)? También el escudero montaba un espectáculo en defensa de su honra, y así lo subraya el narrador refiriéndose a las apariencias y a lo que la gente ignora:

¡Bendito seáis Vós, Señor —quedé yo diciendo-, que dais la enfermedad y ponéis el remedio. ¿Quién encontrará a aquel mi señor que no piense, según él contento de sí lleva, haber anoche bien cenado y dormido en buena cama, $y$, aun agora es de mañana, no le cuenten por muy bien almorzado? ;Grandes secretos son, Señor, los que Vós hacéis y las gentes ignoran! (LT, 83) 
De nuevo el tema de estas palabras se refiere a un espectáculo destinado a mantener un escenario que, en realidad, está hueco. Pero ¿quién será capaz de despejar ese secreto al que se alude Lázaro narrador? Los poderosos no pueden advertirlo porque son precisamente los destinatarios del espectáculo, ni siquiera los iguales por la misma razón. No tienen perspectiva. El argumento que defiende el erasmismo del Lazarillo se apoya precisamente en que al igual que ocurre en la obra de Erasmo, Elogio de la locura, hay alguien que dice la verdad y pone al descubierto la hipocresía de determinados agentes sociales ${ }^{20}$. Sin embargo, vale la pena hacer notar que Lazarillo no dice la verdad porque sufra el tipo de locura que elogia Erasmo, sino por su posición de subalterno.

Lo que él descubre no proviene de ninguna sabiduría o actitud alumbra$\mathrm{da}^{21}$, ni tampoco porque tenga alguna clase de deseo de ir más allá de las apariencias, tampoco se encuentra en la posición de Lucio, el protagonista de $E l$ asno de oro, pues éste tampoco pertenecía a los estratos sociales más bajos. Lo peculiar del Lazarillo es que los secretos se le descubren dado que en su posición todos los personajes que se encuentran con él realizan abreacciones $^{22}$. Al hacerlo, revelan qué hay tras sus máscaras. El Lazarillo de Tormes proporciona, en este sentido, un modelo de análisis político que trasciende su época, pasa por la filosofía de la historia de Walter Benjamin y llega al Grupo de Estudios Subalternos.

\section{VI}

La tradición de estudiosos que ha interpretado el Lazarillo de Tormes como obra literaria de protesta y sátira social es larga. J. Antonio Maravall (1986: 267) habló de «dura crítica antiseñorial», y en términos semejantes se expresaron A. D. Deyermond (1975), Helen H. Reed (1984) o Mario González (1988), entre otros muchos ${ }^{23}$. Sin embargo, el modelo de análisis político del Lazarillo posee una especificidad que vale la pena detallar, si quiera de forma condensada. A la luz de las investigaciones de M. Bajtín (1974, $1989)^{24}$, no resulta difícil adscribir el Lazarillo de Tormes a los fenómenos

20 Véase a este respecto Alfred Morel-Fatio (1888). También Francisco Márquez Villanueva (1968).

21 Sobre el vínculo entre el Lazarillo y los iluminados véase, por ejemplo, Manuel J. Asensio (1959).

22 Para la noción de «abreacción» en su sentido psicoanalítico véase J. Laplanche y J.-B. Pontalis (1983: 1-2). Véase, asimismo, el clásico trabajo de Antonio Vilanova (1983).

23 Para un buen resumen de las diferentes interpretaciones del Lazarillo véase Alberto Martino (1999: I, 315-378).

24 Véase, por ejemplo, el trabajo de Stanislav Zimic (2000). 
carnavalescos. Y, sin embargo, la potencia de este texto surge de la diferencia que mantiene tanto en relación a tales fenómenos como a los géneros y discursos institucionales del siglo XVI. Para apreciarlo, preguntemos si las siguientes palabras de Bajtín pueden explicar adecuadamente el Lazarillo:

Todos esos ritos y espectáculos organizados a la manera cómica, presentaban una diferencia notable, una diferencia de principio, podríamos decir, con las formas del culto y las ceremonias oficiales serias de la Iglesia o del Estado feudal. Ofrecían una visión del mundo, del hombre y de las relaciones humanas totalmente diferente, deliberadamente no-oficial, exterior a la Iglesia y al estado; parecían haber construido, al lado del mundo oficial, un segundo mundo y una segunda vida (...) Esto creaba una especie de dualidad del mundo (Bajtín, 1974: 11) [el énfasis es del autor].

No cabe duda de que la narrativa del Lazarillo vuelve del revés las narrativas centradas en héroes caballerescos (Amadís de Gaula, etc.). En sus inicios, el texto relata la genealogía del protagonista del mismo modo que se hacía a propósito de los grandes héroes, pero sin duda subvirtiendo la alta alcurnia y reemplazándola por unos humildes orígenes. El personaje Lazarillo no proviene de ninguna geografía fantástica, ni sus padres eran reyes o personas privilegiadas, sino de una aldea de Salamanca y del río Tormes. La comparación entre los nombres «Amadís de Gaula» y «Lazarillo de Tormes» habla bien a las claras del tipo de inversión que el segundo provoca en el primero. ¿Es esto una parodia? Sin duda, pero ello no significa que su rasgo principal sea el humor.

Que los orígenes del Lazarillo, a diferencia de los de los héroes, remitan a la pobreza no es cómico, es lamentable. Muchas veces se interpreta la parodia como sinónimo del humor, y ello es una equivocación en muchos casos.

A fin de cuentas, iniciándose de esa manera, el Lazarillo provoca una cuádruple exclusión: en relación a la clase (por ser extremadamente pobre), en relación a la ley (su padre era ladrón y él mismo será mendigo, actividad

${ }^{25}$ Escribe Manuel Fernández (1989: 179) a este respecto: «Contra el vagabundeo de los pobres, cuya tendencia al nomadismo venía dada por la naturaleza de su propio oficio, buscando de un año para otro los lugares que hubieran tenido más prósperas cosechas, o simplemente la rotación de las fiestas lugareñas, luchan los Austrias Mayores. Reiteradas veces prohíbe Carlos $\mathrm{V}$ ese vagabundeo». El propio narrador del Lazarillo da cuenta de ello cuando en el tratado acerca de su estancia con el Escudero escribe: «Y fue, como el año en esta tierra fuese estéril de pan, acordaron el Ayuntamiento que todos los pobres extranjeros se fuesen de la ciudad, con pregón que el que de allí adelante topasen fuese punido con azotes» (LT, 93). 
prohibida en ciertas fases del siglo XVI $)^{25}$, en relación a la raza (su «padrastro» era negro) y en relación al sexo (su madre era prostituta y él es lo suficientemente pasivo como para ser objeto de una sodomía real o simbólica). Esa cuádruple exclusión convierte al Lazarillo en un subalterno riguroso, incapaz de hablar (ahora sí en el sentido de Spivak), e incapaz de actuar (meramente reactivo). Esta es la razón por la que el Lazarillo de Tormes supone un análisis político del problema de la subalternidad en el siglo XVI y más allá.

Ya en 1931 Marcel Bataillon negaba que el Lazarillo fuera una sátira social y el argumento principal que sostenía para ello era que la representación de la sociedad y de las clases era muy fragmentario e incompleto. Por ejemplo, no aparecen, decía, los propietarios de las tierras, ni los mercaderes, ni la magistratura, ni el ejército, etc. (Bataillon, 1958: 5-6). Es el mismo argumento que empleaba para afirmar el carácter lúdico de esta «novelita», tal y como se ha puesto de relieve en el inicio de este ensayo. Sin embargo, y al margen de lo que he comentado en esos inicios en torno a los problemas de la noción de lo «estético» en el siglo XVI, tal interpretación incurre en la ceguera de no ver que la única razón por la que todos estamentos no aparecen en la novela es la propia marginalidad extrema del Lazarillo.

Lo que este texto toma en consideración son los márgenes de esa sociedad y aquella franja social que linda con ella. Dicho de otra manera: se trata de una narración acerca de los diferentes tipos de subalternidad, y acerca de la diferencia entre el subalterno que se convierte en dominante en aquellos contextos en que puede ejercer su poder (el ciego, el clárigo de Maqueda, el escudero, el buldero, etc.), y el subalterno que no puede ejercer esa función de dominante en ningún contexto. A ello hay que sumar el valor sinecdóquico de los tipos sociales que aparecen en la novela. Los tipos que menciona Bataillon son precisamente aquellos que en general constituyen la clase de los poderosos, y aunque no aparezcan en la novela, lo que en ella se presenta y se ve son los efectos de un sistema social en el que, durante el tránsito al capitalismo, unos poseen la tierra y las posesiones, y otros las sufren. Tales tipos aparecen por defecto.

Por todo ello, las palabras de Bajtín no son aplicables al Lazarillo, esta narración no pertenece al registro carnavalesco y en ningún momento - y aquí está la clave - construye un segundo mundo y una segunda vida. En el Lazarillo, y a diferencia de aquellas tesis como las de Ortega y Gasset (1954³), Américo Castro (1935) o José Antonio Maravall (1986), no hay una crítica o sátira social realizada desde una posición exterior al entramado social del que se habla, sino un análisis político del problema de la subalter- 
nidad desde el interior de la subalternidad misma. Entiendo que decir del Lazarillo que es un «pícaro» no deja de ser un adjetivo injusto, ciego, que induce a la equivocación a la hora de comprender este personaje. El Lazarillo no construye un segundo mundo y una segunda vida, sino que se sitúa en esta vida, en este mundo, en la sociedad misma que está saboteando, y su punto de vista es rabiosamente interno.

Eso es, entre otras cosas, lo que un análisis narratológico del punto de vista nos descubre, y eso es lo que la narratología no acertaba a ver. El pretendido pesimismo del Lazarillo desaparece si se tiene en cuenta que, desde el pathos y afecto narrativos, nos permite pensar lo que la subalternidad puede y no puede, así como las razones por las que un subalterno y una subalterna pueden estar poco dispuestos a llevar a cabo la revolución. En cuanto a este punto me parece del todo inaceptable la interpretación de Molho (1977: 90) cuando acusa al Lazarillo de haber llevado a cabo «una ignominiosa ascensión en la carrera del deshonor» ${ }^{26}$. ¿Deshonor? ¿Acaso el padecimiento de hambre y las acciones que conducen a alguien a solventar ese problema puede considerarse deshonroso? Molho ignora el análisis político del problema de la subalternidad y su lógica que el Lazarillo de Tormes desarrolla. ¿Pero de qué subalternidad estamos hablando? De aquella, cierto, pero también de la nuestra.

\section{REFERENCIAS BIBLIOGRÁFICAS}

AHMAD, A. (1992). In Theory, Classes, Nations, Literatures. London: Verso.

ALTHUSSER, L. (1969). «Ideología y aparatos ideológicos del estado (notas para una investigación)». En Escritos. Barcelona: Laia, 1974.

ANDERSON, B. (1983). Imagined Communities. Reflections on the Origin and Spread of Nationalism. London: Verso. Trad. esp. Comunidades imaginadas: reflexiones sobre el origen y la difusión del nacionalismo. México: FCE, 1993.

ASENSI PÉREZ, M. (2006). Philippe Sollers, Tel Quel y la génesis del postestructuralismo francés. Valencia: Tirant lo Blanch.

${ }^{26}$ En una línea semejante están L. J. Woodward (1965) y George A. Shipley (1983). Lo más llamativo de estas interpretaciones es que conciben al Lazarillo como responsable de la degradación moral a la que se ve sometido. Por lo menos, Manuel Ferrer-Chivite responsabiliza de la degradación moral de Lázaro a la sociedad española del siglo XVI, acercándose con ello al tipo de análisis político del Lazarillo. De este autor véase, entre otras obras dedicadas al mismo tema, (Ferrer-Chivite: 1983). 
ASENSIO, M. J. (1959). «La intención religiosa del Lazarillo de Tormes y Juan de Valdés». Hispanic Review 27, 78-102.

BAJTÍN, M. (1974). La cultura popular en la Edad Media y en el Renacimiento. El contexto de François Rabelais. Barcelona: Barral Editores.

- (1989). Teoría y estética de la novela. Madrid: Taurus.

BARTHES, R. (1963, 1979). Sur Racine. Paris: Seuil.

BATAILLON, M. (1958). «Introduction» a La vie de 'Lazarillo de Tormes'. Paris: Aubier.

BOLTANSKI, L. y CHIAPELLO, E. (1999). El nuevo espíritu del capitalismo. Madrid: Akal.

CASTRO, A. (1935). «Perspectiva de la novela picaresca». Revista de la Biblioteca, Archivo y Museo del Ayuntamiento de Madrid XII. 46, 123-143.

CHATURVEDI, V. (ed.) (2000). Mapping Subaltern Studies and the Postcolonial. London: Verso.

COBARRUVIAS, S. (1977). Tesoro de la Lengua Castellana o Española. Madrid: Ediciones Turner.

CROS, E. (1976-1977). «Semántica y estructuras sociales en el Lazarillo de Tormes». Revista Hispánica Moderna 39, 79-84.

DEBORD, G. (1968). La sociedad del espectáculo. Valencia: Pre-Textos, 2003.

DERRIDA, J. (1967). La voz y el fenómeno. Valencia: Pre-Textos, 1985.

- (1972). La dissémination. Paris: Seuil. [Originalmente publicado en la revista Tel Quel en 1968]. En español, La diseminación. Madrid: Fundamentos, 1975.

DEYERMOND, A. D. (1975). Lazarillo de Tormes. Critical Guides to Spanish Texts, n. ${ }^{\circ}$ 15. London: Grant \& Cutler.

EVEN-ZOHAR, I. (1990). Polysistem Studies volumen monogáfico de Poetics Today 11, 1.

FERNÁNDEZ, M. (1989). La sociedad española en el Siglo de Oro. Madrid: Gredos.

FERRER-CHIVITE, M. (1983). «Lázaro de Tormes y sus zapatos: Una interpretación del tratado IV a través de la literatura y el folklore». En $\mathrm{Li}$ - 
teratura y folklore: Problemas de Intertextualidad, J. L. Alonso Hernández (ed.), 243-269. Acta Salmanticensia. Serie Varia, 45. Universidad de Groningen-Universidad de Salamanca.

GADAMER, H. G. (1960). Verdad y Método. Salamanca: Sígueme, 1977.

GARCÍA BERRIO, A. (1977, 1980). Formación de la teoría literaria moderna: la tópica horaciana en Europa. Madrid: Cupsa; y Formación de la teoría literaria moderna (2): teoría poética del Siglo de Oro. Murcia: Universidad de Murcia.

GARCÍA DE LA CONCHA, V. (1981). Nueva lectura del «Lazarillo». El deleite de la perspectiva. Madrid: Castalia. Con nueva edición en 1993.

GARRIDO DOMÍNGUEZ, A. (1996). El texto narrativo. Madrid: Síntesis.

GENETTE, G. (1972). Figures III. Paris: Seuil. Trad. esp. Figuras III. Barcelona: Lumen, 1989.

GEORGE, A. y SHIPLEY, G. A. (1983). «The Critic as Witness for the Prosecution: Resting the Case Against Lázaro de Tormes». En Creation and Re-creation: Experiments in Literary Form in Early Modern Spain. Studies in Honor of Stephen Gilman, Ronald E. Surtz y Nora Weinerth, 105-124. Newark-Delaware: Juan de la Cuesta.

GODZICH, W. (1977). Literaturas emergentes y literatura comparada. Valencia: Ediciones Episteme.

GONZÁLEZ, M. (1988). O romance picaresco. Sao Paulo: Editora Atica.

GREIMAS, A. J. y COURTÉS (1979). Semiótica. Diccionario razonado de la teoría del lenguaje. Madrid: Gredos, 1982.

GUEVARA, A. de (2004). Epístolas familiares, Obras completas III. Madrid: Fundación José Antonio de Castro.

HEIDEGGER, M. (1927). Sein und Zeit. Tübingen: Neomarius Verlag \&58. Ed. inglesa: Being and Time. New York: Harper \& Row, 1962.

HILLIS MILLER, J. (1985). The Linguistic Moment. From Wordsworth to Stevens. Princeton, New Jersey: Princeton University Press.

IGLESIAS SANTOS, M. (1994). «El sistema literario: teoría empírica y teoría de los polisistemas». En Avances en Teoría de la literatura, Darío Villanueva (comp.), 309-356. Santiago de Compostela: Universidad de Santiago de Compostela.

La Tribune de Genève, 3 de agosto de 1963. 
LABERTIT, A. (1972). Introduction à l'étude critique. Textes espagnoles. Paris: Saillard.

LAPLANCHE, J. Y PONTALIS, J.B. (1983). Diccionario de psicoanálisis. Barcelona: Labor.

MAN, P. de (1979). Allegories of Reading. Figural Language in Rousseau, Nietzsche, Rilke, and Proust. New Haven and London: Yale University Press. Trad. esp. Alegorías de la lectura. Lenguaje figurado en Rousseau, Nietzsche, Rilke y Proust. Barcelona: Lumen, 1990.

MARAVALL, J. A. (1973³). El mundo social de 'La Celestina'. Madrid: Gredos.

- (1986). La literatura picaresca desde la historia social (Siglos XVI y XVII). Madrid: Taurus.

MÁRQUEZ VILLANUEVA, F. (1968). «La actitud espiritual del Lazarillo de Tormes». En Espiritualidad y literatura en el siglo XVI, 67-137. Madrid: Alfaguara.

MARTINO, A. (1999). Il Lazarillo de Tormes e la sua ricezione in Europa (1554-1753), 2 vols. Pisa-Roma: Istituti Editoriali e Poligrafici Internazionali.

MIGNOLO, W. (1991). «Canons a(nd)cross-cultural boundaries (or, whose canon are we talking about?)». Poetics Today 12. 1, 1-28. Traducción española «Los cánones y (más allá de) las fronteras culturales (o ¿de quién es el canon del que hablamos?)», en El canon literario, Enric Sullá (ed.) (1998), 237-270, Madrid: Arco / Libros.

MOLHO, M. (1977). Semántica y poética. Barcelona: Editorial Crítica.

MOREL-FATIO, A. (1888). Recherches sur Lazarillo de Tormes. En Études sur l'Espagne. Première série, A. Morel-Fatio, 112-176. Paris: F. Vieweg.

NAVARRO DURÁN, R. (2003). «Introducción» a La vida de Lazarillo de Tormes, y de sus fortunas y adversidades. Barcelona: Ediciones Octaedro.

ORTEGA Y GASSET, J. (1954³). La picardía original de la novela picaresca. En Obras completas, tomo II: El Espectador (1916-1934). Madrid: Revista de Occidente.

PICARD, R. (1965). Nouvelle critique ou nouvelle imposture. Paris: J.-J. Pauvert.

POUILLON, J. (1970). Tiempo y novela. Buenos Aires: Paidós. 
REED, H. H. (1984). The Reader in the Picaresque Novel. London: Tamesis Books Limited.

RICO, F. (1970). La novela picaresca y el punto de vista. Barcelona: Seix Barral, 1982.

RICO, F. (ed.) $\left(1995^{10}\right)$. Lazarillo de Tormes. Madrid: Cátedra.

ROBINSON, L. S. (2007). «Treason Our Text: Feminist Challenges to the Literary Canon». Tulsa Studies in Women's Literature 2. 1, 105-121.

SANTONJA, G. (ed.) (2000). Vida del Lazarillo de Tormes castigado o Lazarillo de la Inquisición. Madrid: Nuevo Milenio.

SOLLERS, Ph. (1968). «Dante y la travesía de la escritura». En La escritura y la experiencia de los límites. Valencia: Pre-Textos, 1978.

- (2000). La Divine Comédie. Paris: Gallimard.

SPINGARN, J. E. (1963). A History of Literary Criticism in the Renaissance. New York: Harcourt, Brace \& Wordl.

SPIVAK, G. Ch. (1988). «Can the subaltern speak?». En Marxism and Interpretation of Culture, Cary Nelson y Lawrence Grossberg (eds.), 271313. Urbana and Chicago: University of Illinois Press.

- (2000). «The New Subaltern: A Silent Interview». En Mapping Subaltern Studies and the Postcolonial, Vinayak Chaturvedi (ed.), 324-340. London: Verso.

VILANOVA, A. (1983). «Fuentes erasmistas del escudero del Lazarillo». En Serta Philologica F. Lázaro Carreter natalem diem sexagesimus celebrante dicata. II: Estudios de literatura y crítica textual, 557-587. Madrid: Cátedra.

VOLOSHINOV, V. N. (1929). El marxismo y la filosofía del lenguaje. Madrid: Alianza Editorial, 1992.

WEINBERG, B. (1961). A History of Literary Criticism in the Italian Renaissance. Chicago: The University of Chicago Press.

WOODWARD, L. J. (1965). «Auto-Reader Relationship in the Lazarillo de Tormes». Forum for Modern Language Studies 1, 43-53.

ZIMIC, S. (2000). Apuntes sobre la estructura paródica y satírica del «Lazarillo de Tormes». Madrid: Iberoamericana. 